\title{
Mining processes of brick products in the Czech Republic
}

\author{
Jan Fiala ${ }^{1, *}$, Miroslav Lapka $^{2}$, Jan Fiala jun. ${ }^{1}$, and Milan Mikolas ${ }^{2}$ \\ ${ }^{1}$ Brick factory of Sterboholy, 10200, Praha-Sterboholy, Nedokoncena, 163, Czech Republic \\ ${ }^{2}$ VSB-Technical University of Ostrava, 70800, Ostrava, 17 listopadu, 2172/15, Czech Republic
}

\begin{abstract}
First technological process, which ceramic producers of ceramic products use for their future ceramic product is mining process. Mining methods, Transport methods and processing methods are basic technological processes. The process of drying, firing and shaping of brick products are specific. Babylonian gardens, Hagia Sofia, are one of the most beautiful churches that has ever been built. The great Wall of China, medieval castle Malbork from northern Poland not far from Gdansk's bay which resembles small town, Skyscraper Chrysler Building in New York are the outstanding brick creations in the world. All of these buildings have one thing in common and that is material from which they were built. The material is brick, one of the simplest, the most beautiful, the most universal and the oldest building product which is known for moreover than 10000 years [1]. Brick association of Czech and Moravia, nowadays unites 6 regular members with 19 plants where are created fired building materials. Furthermore it unites 7 associated members who ensure various services for brickmakers and 7 honorary members. Producers, members of brick association represent $92 \%$ of Mason material capacity in the Czech Republic and $100 \%$ of fired roofing tile capacity.
\end{abstract}

\section{Introductoin}

First step to brick product begins with excavation. All producers of ceramic sortiment in the Czech Republic daily come over excavation problems and on space more than $12.5 \mathrm{~km}^{2}$ and its deposits are estimated at $1550 \mathrm{mil} \mathrm{m}$ of brick materials which are basics for future products. All producers mine their deposits by mining methods. The mining takes place inside face working place, working district.

Brick Materials can be found on shallow placed deposits with simple structure. The materials are usually easily separable. Tose materials are mostly clay, marl, duststone, sandstone, slates, shales, marlstones. The consistance of these materials is very specific, diverse and ordinarily in each locality different. It is Palaeozic to Quaternary sediment. After removal of outer layers of topsoil and next layers the excavation begins [2].

\footnotetext{
${ }^{*}$ Corresponding author: j.fiala9@gmail.com
} 


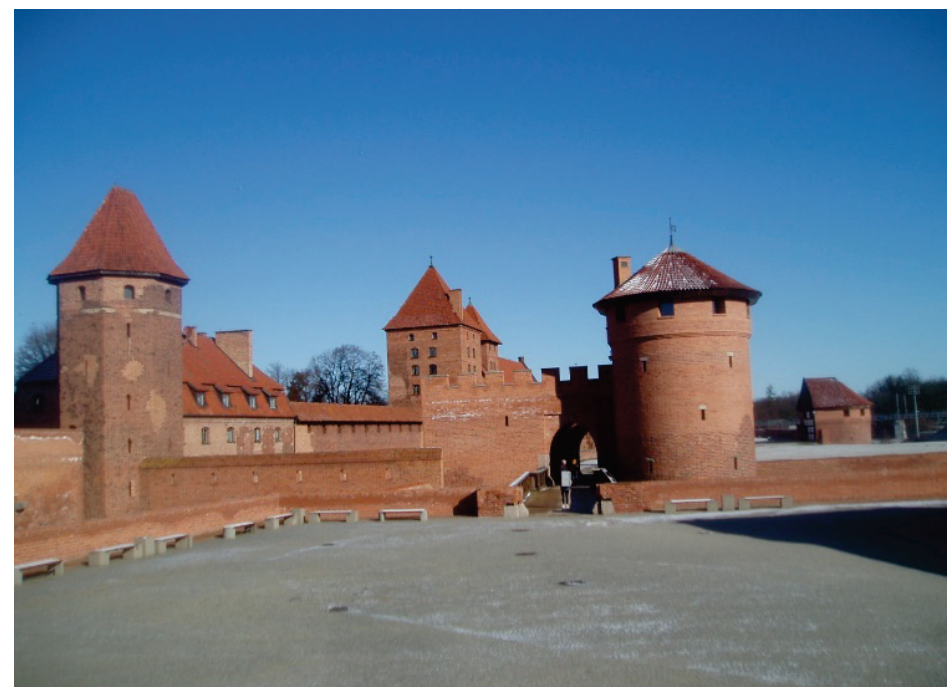

Fig. 1. Castle Malbork, Poland, Source: Ing. Jan Fiala 2018.

\section{Excavation}

The most usual way of excavation is usage of spade or bucket diggers, loaders and dozers.

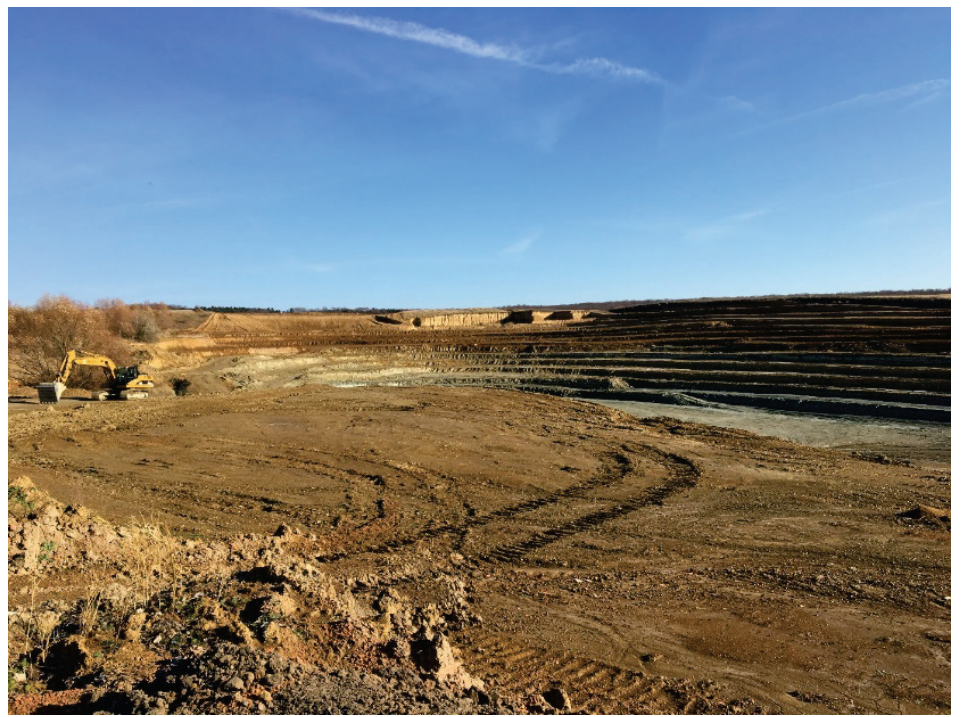

Fig. 2. Excavation premise of surface mining, Source: Wienerberger.

Brick factories which do not have so called "odlezarna" (separate space for storage of mining materials), the material is gathered directly from heaps or individual mining layers. Its movement in the place of excavation is under weather influence. The working processes are clearly specified by the organization and abiding of them is strictly required by work shift technical expert. Because we are talking about cohesive materials the process of continuance by individual layers is of high importance. The width of working space but mainly angles of slopes is specific for this type of material. Due to the stickiness of the material each individual organization has to drain all the water from these mining premises. 
The brickmakers encounter with mining from dump pile but also with the mining in grown state. The excavation is cyclical but also continual. Cyclical excavation is done by spade excavators, front-loaders and other devices. Usage of spade excavators is usually connected with cyclical transportation by transportation truck. These move the material nearer for further use.

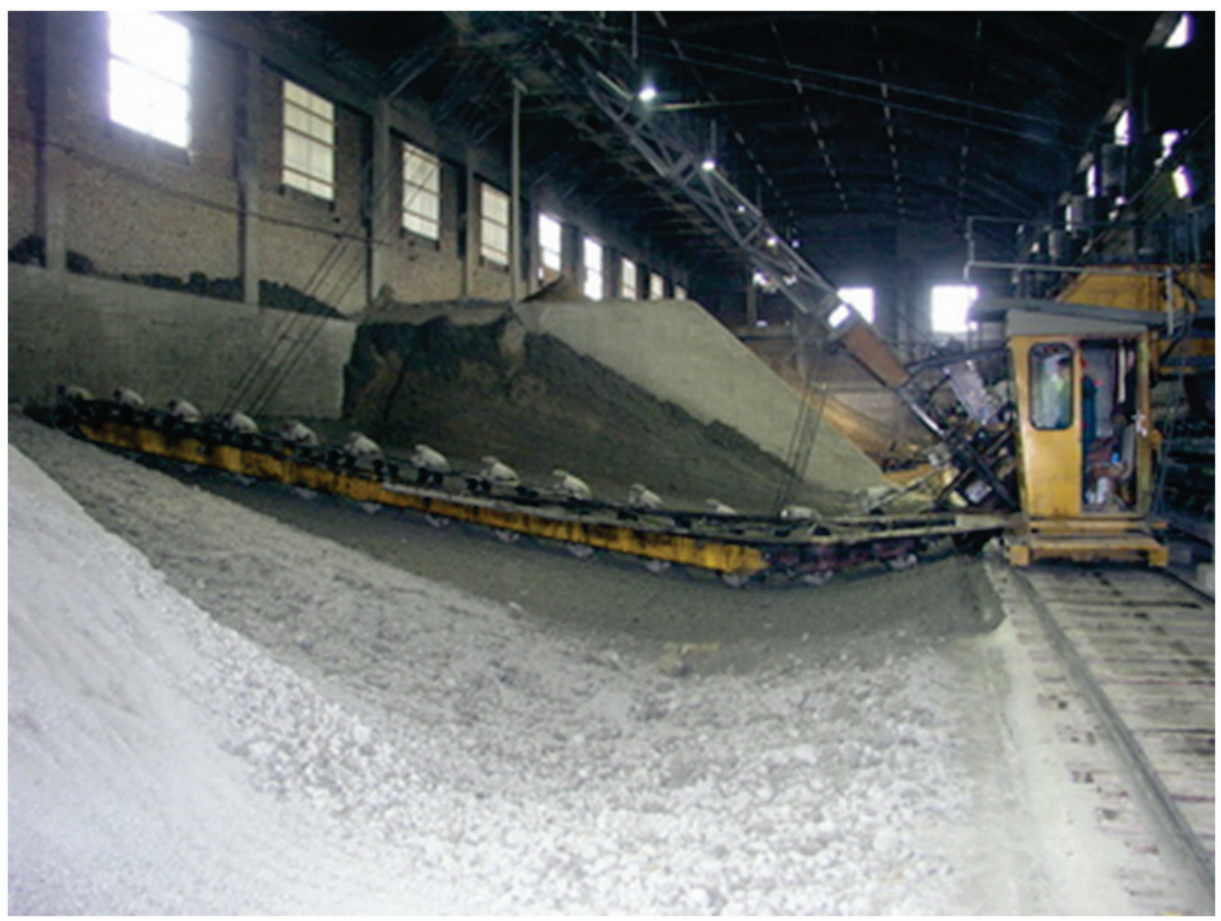

Fig. 3. "Odlezarna" Source M. Vavro 2004.

They extract raw materials directly form piles or individual mining levels. Their movement in the mining area is subjected to weather conditions. Work procedures are clearly specified by the organization and their adherence is strictly required by the quarry of the main shift technician.

Since these are non-cohesive raw materials, emphasis is placed on movement along individual levels, where the width of working platforms and especially the slope angels, which are specific to this kind of material, must be observed.

Due to the tackiness of the material, the individual organizations must properly remove all water from the extraction area. Brickmakers encounter both mining and dump mining, while mining is both cyclical and continuous. Cyclic mining is done by shovel excavators, front loaders and other equipment. The use of shovel excavators tends to be associated with cyclical transport secured by freight wagons. These bring the material to the next method of mining.

With use of bucket excavators, which are part of continual mining machinery, the material is transported to the box-shaped feeders. There is created supply of material so the input of materials could be continual. Second method how to replenish materials into the box-shaped feeders, containers of materials for producing plant is continual replenishment by frontal loader. Individual production plants can have even more box-shaped feeders series placed and in each one can be different type of material.

There can be different type of materials but also admixtures, which help to improve characteristics of future product. 


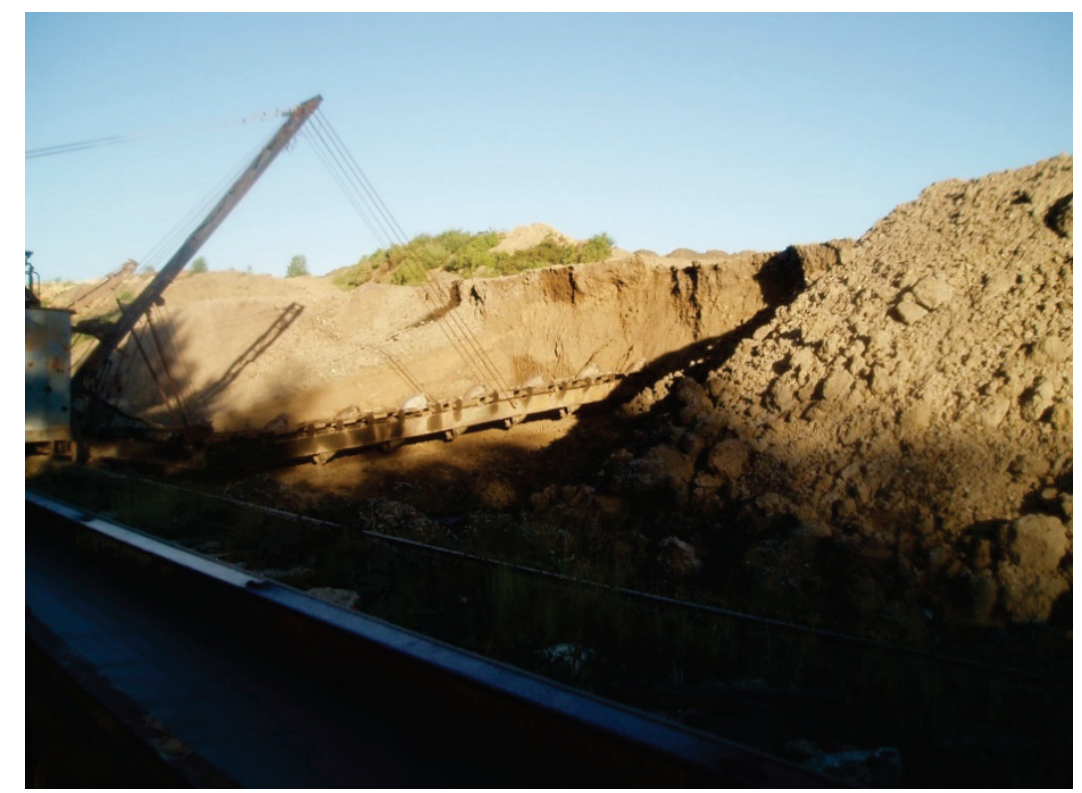

Fig. 4. Bucket excavator, Source: Ing. J. Fiala 2019.

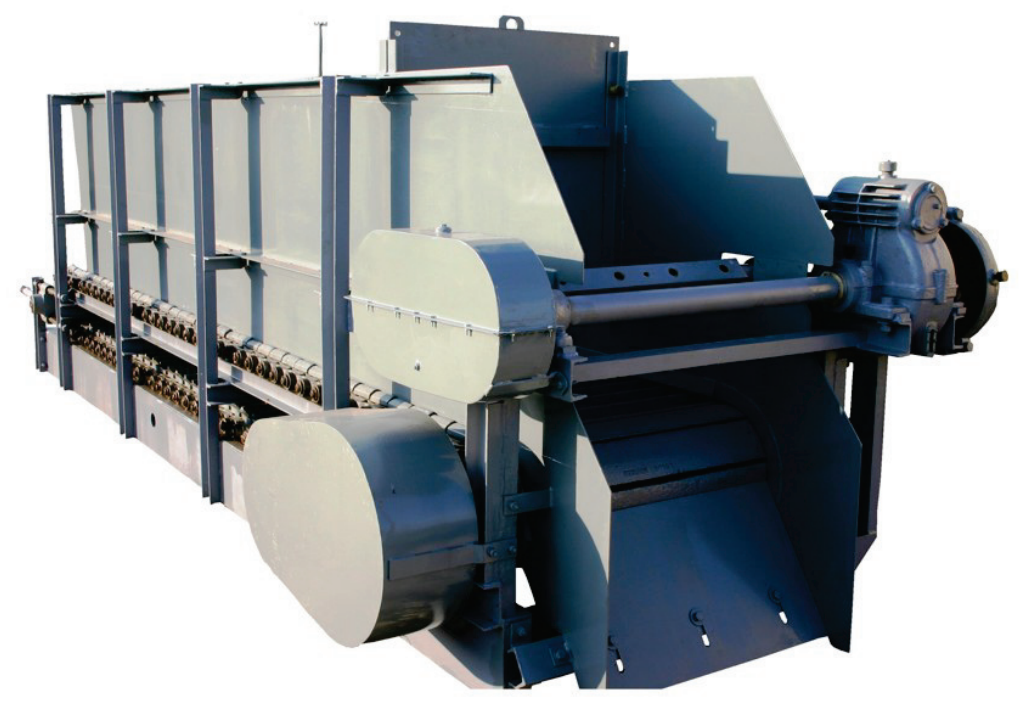

Fig. 5. "Box-shaped feeder", Source: CTS.

\section{Transportation}

Part of mining process is transportation, which is closely connected with it. Organizations which extract raw brick materials we can meet up with various ways of transportation. Those are continual and cyclical. Throughout our history we could witness nowadays not anymore used transportation by cableways or ropeways or cable railway. This method is used due to necessity of dealing with long-range transportation, but as mentioned before these are not being used nowadays.

Another long-lived method of transportation which is not being used anymore was use 
of diesel machines and tipping carts, which resembled the carts used in mines and subterranean pits. Nowadays are mostly used cargo vehicles for moving the material closer to the production plants. This is followed by transportation with conveyors which move the material to the box-shaped feeder. These create magazines for individual production plant, or when used in more numbers, serve as magazines for different types of materials and admixtures, so we would be able to batch these materials in variable amounts. It can be refiled by frontal loaders. For the transportation inside the plant or in between individual technological units is used conveyor belt transportation [3].

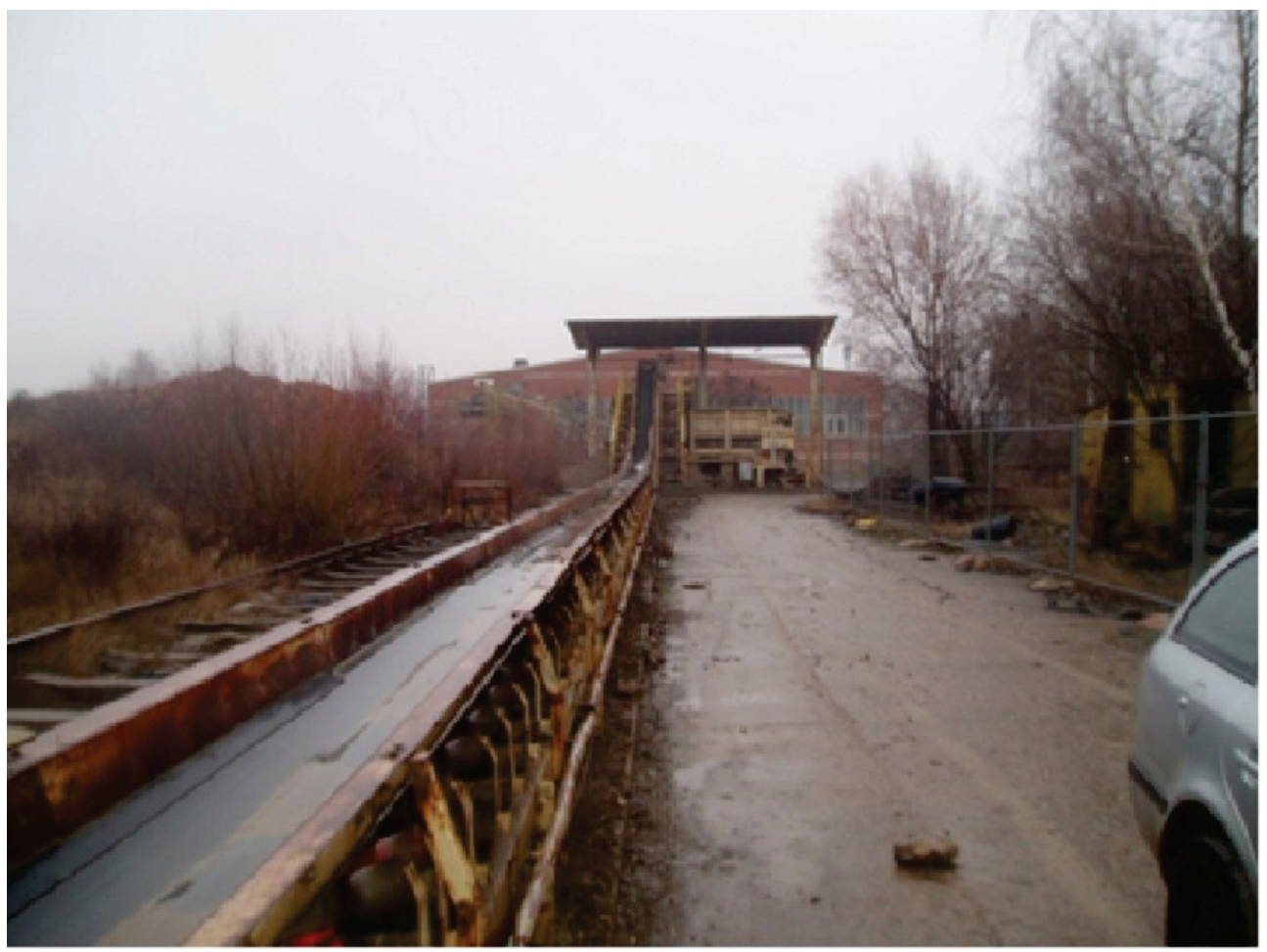

Fig. 6. Conveyor belt, Source: Ing. Jan Fiala 2019.

To ensure the transportation of materials among the individual parts of production plant, different types of conveyor belt transportation are used. Among these are for example sectional steel transporters, classic conveyor belts inset with rubbertextile of various width and structures and lastly are special vertical transporters. The steel section transporters are mostly used for moving materials slowly over short distances. These are mostly wider than classic conveyor belts and in combination with hopper work as feeders of material into other technological parts of production plant. Various grinding or mixing devices or other conveyor belt transportations which follow production technology.

In several production plants instead of these steel section transporters with rubbertextile or steelcore conveyor belt which are characterized by high firmness in traction. Due to being less problematic and having longer lifespan the steel section transporters are better choice. Classic conveyor belts which ensure technological transportation in production plant are mostly inset by soft conveyor belts with width of $400-1000 \mathrm{~mm}$ and firmness of $400-630 \mathrm{~N} \mathrm{~mm}^{-1}$.

The main use of the belts is economical transportation over longer distances, thus these type of belts are placed in horizontal position alternatively can be placed in angles in accordance to the characteristics of individual transported material. The use of profile 
conveyor belts is due to the consistency of input material considerably problematic. The belts allow transportation of materials in relatively high levels of ascent, but the problem arises when the belt needs cleaning of bottom part of the transporter. The material can be highly sticky due to weather conditions or permanent hydrogeological conditions and stickiness is one of the most problematic characteristics of input material in brickmaking due to the transportation.

In horizontal transportation this problem is possible to solve with use of quality wiping technology for smooth conveyor belts, however this type of transportation is not possible to use in small space with high-altitude difference. Transportation technology such as "Flexowell" or transportation with elevator towers, is not possible to use due to the nature of materials. One of few possible ways to solve this is use of so called "sandwich conveyors".

Transporter uses two opposite smooth conveyor belts - one is main load-bearing, second is supporting pressure. Material is poured onto the main belt, supporting belt then fits tightly from above to the transported material and then it is vertically moved. Before or on the place of pouring, the supporting belt move away from main belt. The main advantage lies in the possibility of moving this sticky material under any angel and simple way of cleaning both conveyor belts. The disadvantage is only in harder construction of own conveyor belt [4].

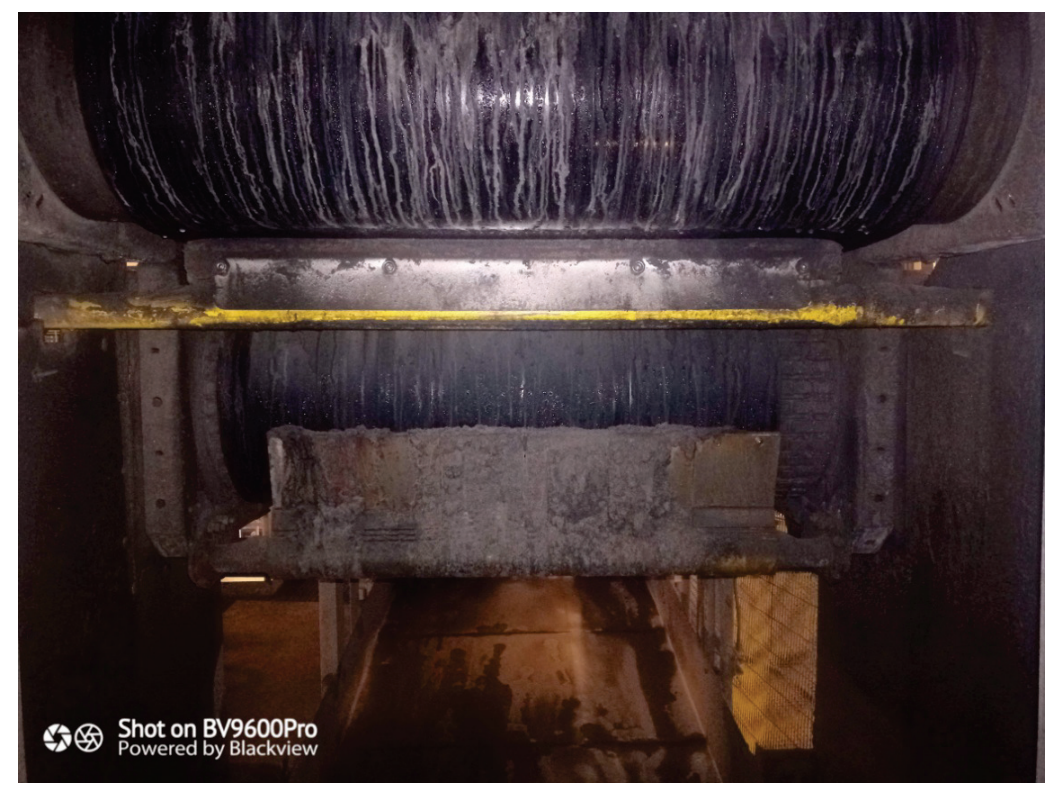

Fig. 7. Sandwich Conveyor, Source: WP systems s.r.o. 2020.

\section{Processing}

Producers of ceramic products use several methods of disjoining materials. Even though it is easily separable material, due to the technological processes producers put considerable emphasis on this part. From history it is known that the first methods of disjoining already take place in face working place, working district. So called overfreezing is used. The basics of the method of separation, which is not financially demanding, is leaving the material in rain so that the materials absorbs more water than from natural humidity. In winter months due to freezing partial cracking, or natural separating starts to occur. Next step is to leave this material lie fallow for two years at least then it can be transported. 


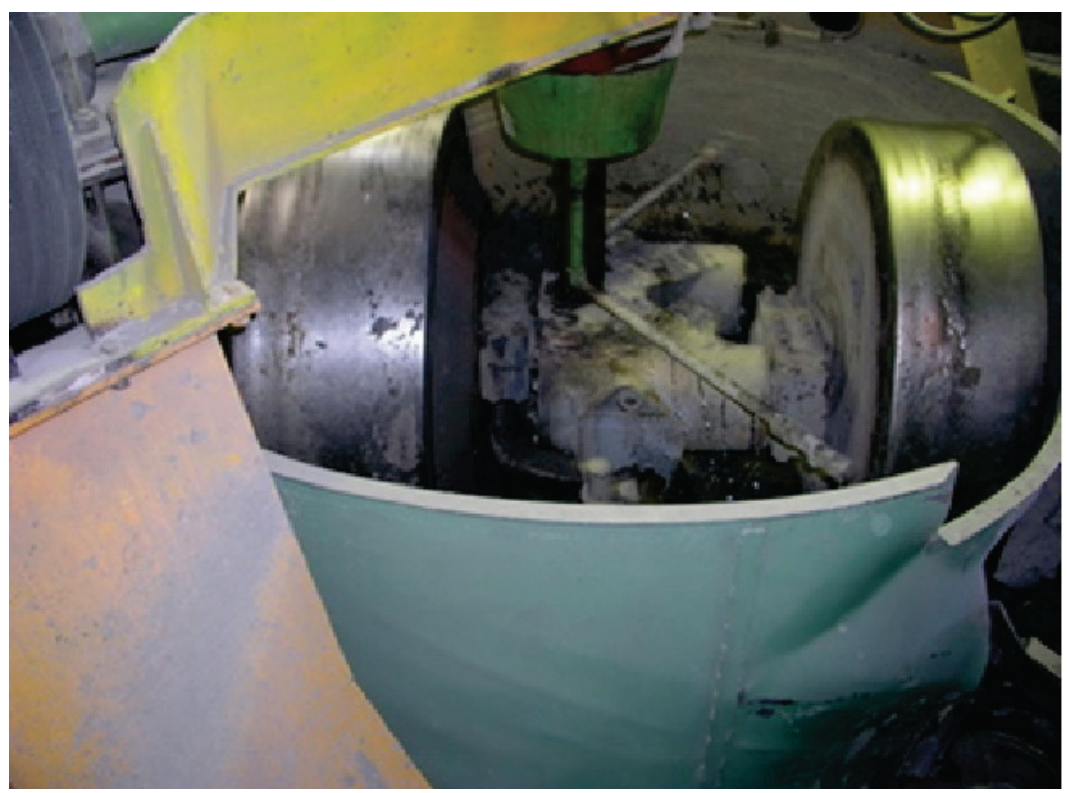

Fig. 8. Wheel mill, Source: M. Vavro 2004.

Into the wheel mill, where does first mechanical disjoining happen alternatively grinding. To the material or materials water is added which helps to better way of processing and next step through the manufacturing line. Next the materials goes into the barrels which grind materials into the needed fraction for press. By this all of the possible methods of transportation and processing are used. Additional technological methods already form the product. This includes pressing, drying, firing and expedition.

\section{Conclusion}

Complete summary of technological methods of excavation and processing brings the readers information from which is apparent that producers of brick products are completely same mining organization to which applies all known methods of excavation and processing as the biggest mining organizations. The only difference is only in the amount of processing materials.

\section{References}

1. J. Hejhalek, J. Fiala, Intro. 3, 24-25 (2017)

2. Brickmaking lexicon Brick association of Czech and Moravia. 16-155 (2007)

3. J. Grygarek, V. Kryl, Systems of preparation and quarrying, Academical publisher University of Mining -Technical university of Ostrava. 27-64 (2000)

4. M. Mikolas, J. Fiala, M. Lapka, J. Fiala jun., Ways of solving problems with abrasive effects of transported materials on technological lines for raw mineral processing, s.r.o., World Multidisciplinary Civil Engineering-Architecture-Urban Planning Symposium WMCAUS 2019 (2019) 